\title{
ACTIVATING CROSS-BOUNDARY KNOWLEDGE: THE ROLE OF SIMMELIAN TIES IN THE GENERATION OF INNOVATIONS
}

\author{
MARCO TORTORIELLO \\ IESE Business School \\ DAVID KRACKHARDT \\ Carnegie Mellon University
}

\begin{abstract}
In this article, we study the conditions under which having ties that span organizational boundaries (bridging ties) are conducive to the generation of innovations. Whereas previous research has shown that bridging ties have a positive impact on innovative performance, our analysis of 276 R\&D scientists and engineers reveals that there are no advantages associated with bridging per se. In contrast, our findings suggest that the advantages traditionally associated with bridging ties are contingent upon the nature of the ties forming the bridge-specifically, whether these bridging ties are Simmelian.
\end{abstract}

The organizational literature on "boundary spanning" has long recognized the informational advantages associated with access to external sources of knowledge and information (Allen \& Cohen, 1969; Allen, Tushman, \& Lee, 1979; Tushman \& Scanlan, 1981). In particular, research has shown that accessing knowledge from across boundaries is an important driver of innovative performance for organizations (Cohen \& Levinthal, 1990), business units (Hansen, 1999; Tsai, 2001), teams (Ancona \& Caldwell, 1992; Reagans \& Zuckerman, 2001), and individuals (Burt, 2004; Perry-Smith, 2006).

However, although spanning boundaries provides access to diverse sources of knowledge, there are also obvious difficulties associated with transferring, integrating, and leveraging the heterogeneous inputs and diverging perspectives available across organizational boundaries (Argote, 1999; Carlile 2004; Dougherty, 1992). Indeed, to the extent that organizational boundaries separate heterogeneous types of knowledge, individuals involved in cross-boundary interactions might struggle to find a common ground to facilitate knowledge in-

Funding for this research was provided by the Ewing Marion Kauffman Foundation, the Fondazione IRI research fellowship, and the HEC Foundation. We particularly thank the Center for Organizational Learning, Innovation and Performance at the Tepper School of Business, Carnegie Mellon University. We would also like to thank Linda Argote, Kevin Boudreau, David Hounshell, and Bill McEvily for helpful comments and suggestions on earlier versions. We also would like to thank the editor and three anonymous reviewers. tegration, and interactions might become strained because of differences in languages and perspectives, lack of common understandings and shared meanings (Bechky, 2003), and coordination problems (Mors, 2010). In spite of the difficulties associated with leveraging cross-boundary knowledge, research on social networks and knowledge management has mostly highlighted the benefits of diverse knowledge provided by bridging ties, paying less attention to the conditions under which knowledge diversity becomes conducive to the generation of innovation. Yet research on absorptive capacity and associative learning has shown that it is easier to absorb diverse knowledge and generate new ideas when source and recipient share some common (not diverse) knowledge base (Ahuja, 2000; Cohen \& Levinthal, 1990; Reagans \& McEvily, 2003). Paradoxically, then, although the diversity of knowledge and information available across boundaries is necessary to spur innovation (Hargadon, 2002), it simultaneously raises obstacles to successful knowledge sharing and integration (Tushman, 1977: 590-591).

In this article, we address this paradox by studying the interplay between social structure and formal organizational boundaries in the generation of innovations. Specifically, we focus on the conditions under which knowledge-sharing ties spanning internal boundaries in a formal organization (i.e., bridging ties) contribute to individuals' ability to generate innovations. Like previous researchers examining social networks and innovation, we argue that the access to diverse knowledge and information provided by bridging ties is critical for in- 
dividuals' innovativeness (Burt, 2004). However, we also argue that the knowledge diversity provided by bridging ties is not sufficient, by itself, to explain variation in individuals' innovative capabilities.

We propose, instead, that not all bridging ties are equal with regard to their innovative potential, and that the extent to which bridging ties are conducive to the generation of innovation depends on the microstructural context in which they are embedded. In considering different levels of bridging, we draw from Simmelian tie theory (Krackhardt, 1998, 1999; Simmel, 1950) to argue that the existence of common third-party ties around a focal bridge substantially changes the nature of the bridging relationship through which knowledge flows. ${ }^{1}$ In particular, we show that when individuals involved in boundary-spanning relationships share common third-party ties, they are more likely to generate innovations than they are when they lack common third-party ties. Bridging relationships embedded in a dense social structure facilitate the formation of common knowledge and shared meanings, reduce frictions due to differences in understanding, and promote the cooperation and coordinated actions that are necessary to integrate and take advantage of diverse sources of knowledge.

Introducing the concept of Simmelian bridges, we make an important contribution to research on intraorganizational social networks and innovation by combining the advantages of bridging ties (e.g., access to novel/diverse knowledge) with the advantages of Simmelian ties (e.g., stability, agreement creating forces, increased cooperation). In the following sections, we describe our development and testing of theory about the unique advantages provided by Simmelian bridging ties in terms of innovation in a study of the knowledge-sharing relationships and patenting activities of 276 members of the $\mathrm{R} \& \mathrm{D}$ division of a large, multinational, hightech corporation.

\section{THEORY AND HYPOTHESES}

At different levels of analysis, and for ties spanning different types of boundaries, the field of management has long recognized the benefits of boundary-spanning ties (Lawrence \& Lorsch, 1967). For instance, McEvily and Zaheer (1999) found that ties bridging firms' boundaries in advice networks ex-

\footnotetext{
${ }^{1}$ A tie is Simmelian when the parties involved are reciprocally and strongly tied to each other and they are both reciprocally and strongly tied to at least one common third party (Krackhardt, 1998: 24).
}

plained differentials in firms' capabilities acquisition. Similarly, other researchers have also shown that ties reaching outside an organization or outside organizational units are significantly related to individual (Cross \& Cummings, 2003) or unit-level performance (Tsai, 2001).

However, although existing empirical evidence seems to provide evidence that bridging ties correlate positively with performance, less attention has been devoted to the mechanisms that facilitate the integration of diverse sources of knowledge. Particularly in the case of organizational innovation, accessing diverse knowledge located across organizational boundaries, albeit necessary, might not be enough to enhance innovative performance (Tushman, 1977). Research on new product development, for instance, corroborates the view that knowledge developed in different functional areas or different areas of technological expertise is important for the generation of innovations (Bechky, 2003; Carlile, 2004; Dougherty, 1992). At the same time, this stream of research also warns against the difficulties associated with successful sharing and recombination of diverse knowledge into innovative outcomes (Carlile, 2002). Building on these insights, and focusing on social ties defined across formal boundaries among organizational units, we argue that the mere access to diverse knowledge provided by bridging ties may not be enough to enhance individuals' innovative capabilities.

\section{Why Mere Bridging Is Not Enough}

For a host of reasons, the diversity of knowledge and perspectives provided by bridging ties does not automatically translate into the generation of innovations (Ahuja, 2000: 431-433; Obstfeld, 2005). As the knowledge available across boundaries tends to be diverse and heterogeneous (Burt, 2000), bridging ties may lack the necessary common base to integrate different knowledge sources (Ahuja, 2000; Cohen \& Levinthal, 1990; Simon, 1985). Moreover, as knowledge located in different parts of an organization is hard to mobilize (von Hippel, 1994), transferring knowledge across boundaries might be difficult or inefficient because of the lack of a common language and shared meanings (Dougherty, 1992; Tushman, 1977).

Another limit to individuals' ability to generate innovations through ties bridging formal boundaries is that having new ideas is fundamentally different from implementing new ideas. As Obstfeld (2005) noted, generating new ideas through the availability of heterogeneous perspectives, and coordinating the actions that are necessary to imple- 
ment those ideas, translating them into innovations, are two distinct aspects of the innovative process. The diversity of knowledge provided by bridging ties is perhaps conducive to the generation of new ideas (Utterback, 1971) but might not be equally conducive to the implementation of those same ideas into actual innovations. For instance, individuals belonging to different parts of an organization or to different organizational units might be subject to competing pressures that limit their ability to coordinate cross-unit tasks and align joint efforts toward the translation of new ideas into innovative outputs.

Besides the ability to leverage cross-boundary knowledge to generate innovations, the willingness to devote time and effort to sharing knowledge with colleagues located in different parts of an organization should not be taken for granted. For example, in an atmosphere of "intraorganizational secrecy and competition" (Hansen, 1999: 87), individuals located in different parts of an organization may be wary of disclosing information that would benefit their counterparts, or their counterparts' units, at the expense of the individuals' own units. Furthermore, even under circumstances in which competition and secrecy are not concerns, there are still costs associated with decisions to share knowledge interacting with others. Individuals acting as sources of knowledge have to devote time and effort communicating what they know to their counterparts (Reagans \& McEvily, 2003), and it is not obvious that this type of cooperation will naturally occur among individuals located in different parts of an organization.

This brief discussion of ability and willingness to transfer knowledge across boundaries suggests that the diversity of knowledge and opportunities available in different parts of an organization comprise only one aspect of the process leading to the development of innovation (Hargadon, 2002). To understand the mechanisms through which bridging ties do lead to the generation of innovations, other characteristics and qualities of the bridge need to be taken into account.

\section{Strong Bridging Ties}

A relevant feature of knowledge-sharing relationships that could help to overcome the limitations of bridging ties discussed in the previous section is tie strength. In this context, "strength" refers to frequency of interaction (Granovetter, 1982; Krackhardt, 1992). Although the strength of bridging ties is generally considered an aside in structural analysis (Burt, 1992: 30), research has shown that specific advantages may be associated with strong ties.
For instance, Hansen (1999) showed that strong interunit ties fared better than weak ones when the knowledge flowing from source unit to recipient unit was highly complex (Hansen, 1999). In a different study, Reagans and McEvily (2003) observed that tie strength was positively associated with ease of knowledge transfer (irrespective of knowledge characteristics), and other research has highlighted advantages of strong ties in intraand interorganizational contexts (Krackhardt, 1992; Uzzi, 1997). In the specific case of innovation, strength of ties, when applied to relationships bridging formal organizational boundaries, can enhance successful transfer of knowledge (Hansen, 1999). For instance, frequency of interaction could help build a common knowledge basis and facilitate mutual understandings. When knowledge is idiosyncratic and context-specific, repeated interactions help to develop heuristics that facilitate the transfer of complex information and support joint problemsolving activities (Uzzi, 1997). In addition, by promoting two-way interactions, strong ties increase reciprocal understandings of complex problems. Lastly, as Granovetter argued, individuals connected through strong ties have "greater motivation to be of assistance and are typically more easily available" (1982: 209). Consequently, tie strength could be an important determinant of the extent to which bridging ties correlate with individuals' ability to generate innovations. Following this logic, we predict that:

\section{Hypothesis 1. Bridging intraorganizational boundaries with strong ties is more strongly associated with the generation of innovation than bridging intraorganizational boundaries with weak ties.}

Tie strength applied to bridging ties is a feature of the dyadic relationship through which two individuals located in different parts of an organization exchange knowledge between themselves. However, a complementary perspective can be obtained by shifting the analytic focus from individual boundary-spanning dyads to the microstructural context in which such dyads are embedded. In the following section, we transition from individual boundary-spanning dyads to the social context in which the boundary-spanning dyads are embedded. In doing so, we introduce the concept of Simmelian bridging ties, describe how they differ from non-Simmelian bridging ties, and discuss the mechanisms through which Simmelian ties bridging organizational boundaries become instrumental in the generation of innovations. 


\section{Simmelian Bridging Ties}

The basic idea behind the concept of Simmelian ties is that the context in which dyadic relationships are embedded has the potential to substantially change their character and quality. In particular, a tie becomes Simmelian when the parties involved in it are reciprocally connected to one other and each is reciprocally connected to another, third party (Krackhardt, 1998). The definition of Simmelian ties closely resembles that of a clique (Dekker, 2006); indeed, a perfectly equivalent definition of a Simmelian tie is that it is a tie embedded in a clique. ${ }^{2}$

Simmel went to great lengths to argue that this qualitative difference was not simply a consequence of such embedded ties being stronger (see Dekker [2006] for a formal discussion of this issue). Nor, Simmel argued, did the size of the clique matter:

Dyads thus have very specific features. This is shown not only by the fact that the addition of a third person completely changes them, but also, and even more so, by the common observation that the further expansion to four or more by no means correspondingly modifies the group. (Simmel, 1950: 138)

This statement underscores his emphasis on the important qualitative differences between isolated dyads and dyads embedded in a clique. According to Simmel's original formulation, transitioning from a dyad to a completely connected triad changes isolated dyadic ties in three major ways: by mitigating the pursuit of individuals' self-interests, by reducing the bargaining power of single individuals, and by facilitating cooperation and conflict resolution (Krackhardt, 1999). We argue that these three elements play a critical role in the innovative process in the context of bridging ties. Specifically, by drawing a distinction between Simmelian bridges (that is, bridges composed of Simmelian ties) and non-Simmelian bridges (that is, bridges composed of ties that are not Simmelian), we seek to provide novel insights about how individuals located in different parts of an organization lever-

2 "Cliques are defined on a graph as a maximal set of three or more nodes (people in this case) all of whom are directly and reciprocally connected to each other. Thus, each pair of people in a clique are Simmelian tied to each other; and conversely, any pair of individuals who are Simmelian tied are co-members of at least one clique" (Krackhardt, 1998: 186). age each others' knowledge to generate innovations (Tushman \& Scanlan, 1981). ${ }^{3}$

Simmelian ties facilitate the formation of shared interests and the pursuit of common goals by mitigating competition and self-interest. This is important, because informational advantages can be quite limited if the parties involved, acting opportunistically, avoid sharing sensitive knowledge and information with each other. In the case of interactions between individuals located in different parts of an organization, obstacles to the full circulation of knowledge and information across boundaries may arise out of fear of a counterpart's opportunistic behavior. Simmelian bridges, being embedded in a clique of reciprocally connected individuals, instead limit selfish behaviors and promote open and complete knowledge sharing among the parties involved.

For similar reasons, in cross-boundary relationships characterized by Simmelian ties, the bargaining power of single individuals becomes less disruptive than it would be in the case of an isolated bridge. Individuals involved in a simple dyadic arrangement have equal footing in the relationship, and if either one decides to leave, the bridging tie is severed and with that, the flow of interunit knowledge. This means that in case of conflict between the parties to an isolated bridge, the threat of leaving could easily break up the tie (Krackhardt, 1999: 185). In a Simmelian structure, on the other hand, common third parties increase the stability of bridging relationships by reducing dissension and facilitating conflict resolution (Burt, 2002; Krackhardt, 1998). The increased stability promotes the formation of common language and shared understandings among the parties involved. Common knowledge is critical to overcoming interpretive barriers and achieving the successful integration of different perspectives (Carlile, 2004; Carlile \& Rebentisch, 2003; Dougherty, 1992). As Carlile and Rebentisch argued, "Without the common means of representing and applying one's knowledge in an across-domain setting, some participants might withdraw from or even hamper the knowledge integration process" (2003: 1191). The stability of Simmelian bridges promotes the development of shared meanings and common understanding, thus

\footnotetext{
${ }^{3}$ It is worth noting that our concept of "Simmelian bridge" has parallels to Dekker's (2006) concept of the "Simmelian broker." The primary difference is that we are applying Simmel's ideas to the dyadic relationship itself, whereas Dekker focused on the implications such structural positions have for an individual actor.
} 
lowering the interpretive barriers that characterize bridging relationships.

One last element that differentiates Simmelian bridges from non-Simmelian bridges is the higher level of cooperation observed in cohesive structures. Relationships embedded in a clique are characterized by norms of cooperation and reciprocity (Coleman, 1988). Individuals with common thirdparty ties are more willing to cooperate by sharing knowledge with each other (Reagans \& McEvily, 2003) because of the positive expectation that these efforts will be reciprocated in the future (Uzzi, 1997). Cooperation becomes a shared value in densely connected structures, and individuals with common third-party ties are naturally inclined to devote time and effort to knowledge-sharing interactions with other members of their clique.

Building on this theoretical stream, we posit that a Simmelian bridge-that is, a Simmelian tie overlaying a hole in a formal structure-is fundamentally different from a non-Simmelian bridge in the sense of easing the process through which heterogeneous sources of knowledge are combined and integrated for the generation of innovations (Tushman, 1977). Formally, we predict:

\section{Hypothesis 2. Bridging intraorganizational boundaries with Simmelian ties is more strongly associated with the generation of in- novation than bridging intraorganizational boundaries with non-Simmelian ties.}

\section{METHODS}

\section{Data}

Our predictions were tested using original data collected in the $\mathrm{R} \& \mathrm{D}$ division of a large multinational and multidivisional high-tech company. In particular, we collected questionnaire and archival data on 276 respondents who were identified by senior management as "all the employees with active research and development duties in the $R \& D$ division." These researchers were spread over 16 labs around the world: 4 in the United States, 10 in Europe, and 2 in Asia. The average lab consisted of 25 individuals. The population studied comprised mostly males (90\%) who were highly educated (9 percent had Ph.D.s; 78 percent, master's degree; and 13 percent, college degrees or less) and had relatively low organizational seniority (average tenure, 5.2 years).

The R\&D division studied was one of the four central functions of the company, whose mission was to "provide the advanced knowledge necessary to establish [name of the company] as the leading company in the market for the next decade." $4 \mathrm{Al}-$ though the population surveyed enjoyed considerable freedom in terms of research interests and objectives, the activities performed in the division had a fairly applied focus. As a senior researcher from one of the major laboratories put it, "There is a widespread agreement among us [researchers in the lab] that at the end of the day we need to come up with something that would eventually generate money for the company." The network data consisted of information on self-reported knowledgesharing ties collected through a sociometric instrument. The survey yielded a response rate of about 89 percent ( 245 actual respondents out of 276 potential respondents). T-test analysis revealed that nonrespondents were not statistically different from the individuals who participated in the study in terms of patent generation, lab location, organizational tenure, or level of education. Our respondents consistently reported that direct access to the knowledge and expertise of their colleagues in different labs was critical to their activities. As an engineer from the largest lab stated, "The information I found on the intranet [about activities carried out in other labs] is not very helpful, maybe a little before beginning a conversation. ... Having direct contacts with my colleagues in other labs is really important for my productivity."

\section{Measures}

Dependent variable. Our dependent variable was the number of patents filed by individuals in the sample. The company made patent data available in the form of monthly $R \& D$ reports used to assess and reward individual performance. For each of the 16 labs studied, the company made available a total of 18 monthly reports, 6 before and 12 after the collection of social network data. Crossexamination of all reports allowed us to identify patent applications filed by respondents in our sample. One can also measure innovative performance in terms of granted patents; however, such an assessment suffers from the introduction of many bureaucratic and legalistic processes that make it a noisier measure of individual performance. In fact, the firm itself considered patent applications a sounder measure of individual-level innovative performance. Indeed, it was the number of patent applications reported in the monthly report that formed the basis for performance review and promotion decisions.

\footnotetext{
${ }^{4}$ This statement comes from an internal company memo.
} 
Independent variables. A dyadic tie exists between a pair of actors, the sender of the tie and the receiver of the tie. But common assessments of the existence or strength of such a tie often depend on a third domain: the perceiver of the tie (the individual who is the source of information about whether the tie exists or not). To be precise about measurements of these ties, and whose assessment is being considered, it is useful to rely on the formalisms developed elsewhere to maintain clarity on these issues (Carley \& Krackhardt, 1996; Krackhardt, 1987).

The network data were derived from two network survey questions: (1) "Please indicate how often you generally go to this person for information or knowledge on work-related topics" and (2) "Please indicate how often this person generally comes to you for information or knowledge on work-related topics" (for both questions, the response scale ranged from 1, "seldom," to 5 , "very frequently"). ${ }^{5}$ The raw data for these assessments can be represented as a triple $V_{i, j, k}$, where $i$ represents the sender of the tie, $j$ represents the receiver of the tie, and $k$ represents the perceiver (questionnaire respondent). Although in some contexts each of these subscripts can vary freely from 1 to $N$, in the current case the respondent was either the sender or receiver. Thus, we restricted ourselves to two special cases of this general form: $V_{i, j, i}$ (respondent $i$ claims that he/she goes to person $j$ for information) and $V_{j, i, i}$ (respondent $i$ claims that person $j$ comes to him/her for information). For example, for the survey question, "How often do you generally go to this person?," $V_{6,2,6}=$ 5 means that person 6 (the respondent) indicated that he/she goes to person 2 "very frequently" for information or knowledge. For the question, "Who comes to you?," $V_{2,6,6}=5$ means that person 6 (the respondent) indicated that person 2 comes to him/ her "very frequently" for information or knowledge.

From these raw data represented as $V \mathrm{~s}$, we created a network relation of "confirmed" ties, $R^{V}{ }_{i, j}$ (Carley \& Krackhardt, 1996). These are ties that are more psychometrically reliable than nonconfirmed ties (Krackhardt, 1990). In matrix form, this relation is defined as:

$R_{i, j}^{V_{i, j}}=\left\{\begin{aligned} \frac{V_{i, j, i}+V_{i, j, j}}{2} & \text { if } V_{i, j, i}>0 \text { and } V_{i, j, j}>0 \\ 0 & \text { otherwise. }\end{aligned}\right.$

${ }^{5}$ If a respondent never interacted with a target at all, the respondent could check "n/a," in which case the answer was coded as 0 .
A simpler, Boolean version of the above definition can also be given:

$$
R_{i, j}= \begin{cases}1 & \text { if } V_{i, j, i}>0 \text { and } V_{i, j, j}>0 \\ 0 & \text { otherwise }\end{cases}
$$

Both of these definitions were useful in our analysis. Simmelian ties are based on the Boolean graph $R$, and strong ties are derived from the valued graph $R^{V}$.

Strong vs. weak ties. As stated above, we measured the raw ties on a 1-5 scale. We categorized ties as strong or weak using the dichotomy 4 and above versus 3.5 and below (recall that confirmed ties $R^{V}$ are the average of the two individuals' responses, hence the possible fractional values). Strong ties, then, were defined as any tie whose value $R^{V}$ was greater than or equal to 4 . Weak ties were the remaining ones-that is, ties whose value $R^{V}$ was smaller than or equal to 3.5 .

Simmelian versus non-Simmelian ties. Simmelian ties, as stated earlier and as described in Krackhardt $(1998,1999)$ and discussed in detail in Dekker (2006), are defined as ties embedded in cliques. Several methods for obtaining Simmelian ties from a set of raw ties exist. We used the direct formulation provided by Krackhardt (1998), according to which a tie from $i$ to $j$ (that is, $R_{i, j}=1$ ) is Simmelian if and only if it satisfies the following two conditions:

$$
R_{j, i}=1
$$

and

$\exists \mathrm{k}$ such that $R_{i, k}=R_{k, i}=R_{j, k}=R_{k, j}=1$.

A non-Simmelian tie from $i$ to $j$ is any tie that does not satisfy these conditions for being Simmelian.

Bridging: E-I index. In general, the E-I index is a measure of the extent to which a party's ties form a bridge across some organizational or social divide (Krackhardt \& Stern, 1988). The relation, $R$, on which the E-I index is calculated varies: sometimes it is the entire set of raw ties, sometimes it is a subset of these ties (Simmelian ties, for example). In our case, for each of the 245 individuals in our sample we considered the distribution of network ties within and across labs. Given a relation among individuals in our sample, the E-I index for any actor $i$ was constructed by considering the difference between the number of external ties and the number of internal ties. Taking $E_{i}$ and $I_{i}$ as the number of external and internal ties, respectively, then the E-I index for actor $i$ is defined as: 


$$
\text { E-I index } \ln _{i}=\frac{E_{i}-I_{i}}{E_{i}+I_{i}} .
$$

In other words, $E_{i}$ is the number of $i$ 's ties that are to/from members of groups other than the group $i$ belongs to (that is, "external" or bridging ties to/ from $i$ ), and $I_{i}$ is the number of $i$ 's ties that are to/from members of the same group that $i$ is a member of (that is, "internal" or nonbridging ties to/from $i$ ). The E-I index ranges from -1 (when all ties to/from $i$ are internal ties) to +1 (when all ties to/from $i$ are external or bridging ties). A value of 0 indicates the special case in which the number of bridging ties precisely equals the number of nonbridging ties for person $i^{6}$

Control variables. Each model in the analysis included controls for a wide array of individualand network-level variables that could provide alternative explanations for the hypothesized relationships between network structure and patent generation. For instance, to account for individuals' idiosyncratic ability to generate patents, we created a dummy variable measuring their prior patenting experience. ${ }^{7}$ This variable was coded 1 if a respondent had filed at least one patent in the three years before the 18 months considered in the study, and 0 otherwise. ${ }^{8}$

Another possible confound was the fact that often lab heads are registered as filing patents developed by researchers in their labs. To control for this, we introduced a dummy variable that identified the lab heads in our sample. We also controlled for the level of education, seniority, and organiza-

\footnotetext{
6 This "special case" condition also permits the vacuous case to be defined. That is, if an individual has no internal ties and no external ties, the E-I index value is also 0 .

${ }^{7}$ As we only had access to company records for the period ranging from 6 months before and 12 months after the administration of the survey, we had to use external sources to measure previous patenting experience. We obtained this information by searching the USPTO database for all the patents filed by respondents in our sample in the three years before our 18-month window. Although this procedure identified patents granted by the USPTO, and our dependent variable referred to patents filed with the company's legal office, our measure of previous patenting experience was still a meaningful indicator of idiosyncratic differences in individuals' ability to generate innovations. The threshold of 3 years was adopted after interviews with company lab managers revealed that the average time-to-patent in this industry is about 2.5 years.

${ }^{8}$ In an analysis not reported here, we also controlled for the number of patents filed in the three years before the time frame considered; results do not change.
}

tional job grade of researchers as a possible indicator of their ability and experience.

Another important control concerned the amount and type of knowledge that each individual obtained from outside the studied organization. In fact, although we study relationships spanning different research labs, our focus is still on intraorganizational ties. However, it is reasonable to expect that knowledge coming from outside their organization represents an important source of variations in individuals' ability to generate innovations (Chesbrough, 2003; Cohen \& Levinthal, 1990; Laursen \& Salter, 2006). For this reason, we decided to control in our models for the type and amount of knowledge sourced from outside the organization. A principal component factor analysis with varimax rotation on eight different sources of external knowledge allowed us to identify two distinct factors: scientific external knowledge and industrial external knowledge. Industrial external knowledge was defined by four items with a Cronbach's coefficient alpha of .76 and a first principal component explaining 63.2 percent of the variance. Scientific external knowledge was also defined by four items; the alpha coefficient was .81, and the first principal component from a factor analysis of the items explained 58.4 percent of the variance. The indicators for the sources of each form of external knowledge were the means of the respective four items.

One last set of control variables allowed us to take into account individuals' relational features, such as the size of their networks (measured as number of ties), the degree centrality of the alters located in other labs to which each ego was connected, ${ }^{9}$ structural holes, and laboratory size (the number of people in ego's lab). Controlling for network size helped to rule out the possible alternative explanation that it was the sheer number of knowledge-sharing ties that predicted variation in individuals' innovativeness. Similarly, by controlling for the degree centrality of alters located in other labs to which an ego is connected, we addressed the alternative explanation that variation in individuals' innovativeness was a result of their having bridging ties to individuals who themselves had very large networks in their own labs.

Past research has used the presence of structural holes (or its counterpart, constraint) as a measure of many of the concepts in this study, including bridging, informational advantages, and closure. To make sure that our results were not simply a reflec-

\footnotetext{
${ }^{9}$ Degree centrality is given by the number of direct ties a given node has.
} 
tion of the effects of this construct, we included the existence of structural holes (Burt, 1992: 55) as a control in our models.

And finally, it is possible that the number of scientists at a lab, or lab size, could affect both the productivity of its members as well as opportunities for interaction. Therefore, we also controlled for lab size in the models. ${ }^{10}$

\section{RESULTS}

Table 1 presents descriptive statistics and the bivariate correlation matrix for our variables. All the variables beginning "bridging" refer to the E-I index calculations for the different types of ties. For example, the variable "bridging direct raw ties" represents the value on the E-I index calculated for a individual based on the set of confirmed ties for that individual. "Bridging Simmelian ties" represents the E-I index calculated on the set of Simmelian ties for that individual, and so forth.

Table 2 shows the results of the models testing our hypotheses. We used negative binomial regression analysis (clustering standard errors by lab) instead of Poisson regression to model patent count because of the overdispersion evident in our data. ${ }^{11}$

Model 1 in Table 2 presents the effects of control variables on patent generation. The only variables significantly associated with patent generation are individuals' level of education and access to scientific external knowledge. This pattern is consistent with our expectations, since individuals with higher degrees (e.g., Ph.D.s) may have developed skills and expertise through their formal training that make them more likely to produce patents than individuals with lower degrees. Similarly, scientific external knowledge is likely to promote individual innovativeness by offering insights about new knowledge developed in universities and other research institutions that may stimulate creative thinking and result in novel applications.

Model 2 of Table 2 shows results of our test of the

\footnotetext{
${ }^{10}$ In additional models not reported here, we controlled for other possible confounds, such as individual status and geographical proximity. For instance, we controlled for individuals' betweenness (Freeman, 1979) and the geographical proximity of individuals for relationships across labs. We found no substantial differences between the models presented here and the models obtained when controlling for these alternative explanations. Results with these additional controls are available from the authors upon request.

${ }^{11}$ We used the Stata function "nbvargr" to evaluate which modeling strategy best suited the distribution of our dependent variable.
}

traditional bridging argument that boundary spanning, or forming a bridge across an entire set of network ties, is positively related to individual innovativeness. We used the E-I index to define the extent to which individuals in our sample had network ties defined within or across organizational boundaries. Our results show that the sign is in the expected direction but that the existence of ties spanning organizational boundaries is not per se significantly associated with individuals' innovative capabilities $(p<0.29)$.

Model 3 shows results of the test of the main effect of Simmelian ties on individual innovativeness. Here, the greater the number of Simmelian ties (e.g., ties embedded in cliques), the lower the likelihood of generating patent applications. This finding is consistent with the traditional explanation of how informational advantages accrue to individuals as a function of their positions in informal networks (Burt, 1992). Specifically, to the extent that an individual is embedded in a dense system of overlapping ties, he or she has access to redundant, instead of novel, knowledge and information. The lack of new knowledge and information should make it more difficult for the individual to generate innovative outcomes, and this is precisely what we observe in model 3.

Model 4 tests for the main effect of having a network composed primarily of strong ties. A negative and significant effect is associated with the number of strong ties; however, the significance of the coefficient for the number of strong ties goes away when it is considered together with the extent of bridging and the number of Simmelian ties (model 5).

In models 6-11, we tested our theory by partitioning the overall network studied into different categories of knowledge-sharing ties and measuring the extent to which they bridged organizational boundaries, using values on the relevant E-I indexes. Thus, these models explore the possibility that the strength of bridging ties matters for reaping the informational advantages provided by boundary-spanning relationships. Specifically, in model 6 we consider bridging weak ties and in model 7 we consider bridging strong ties. Although the signs of the coefficients are positive, both weak and strong bridging ties are not significantly associated with individual innovativeness. Thus, we found no support for our Hypothesis 1. Indeed, this finding suggests that strength of ties per se makes little difference, at least in our context, in the extent to which bridging promotes individual innovativeness.

In models 9 and 10, we tested the distinction between bridging Simmelian ties and bridging nonSimmelian ties. In keeping with Hypothesis 2, we 


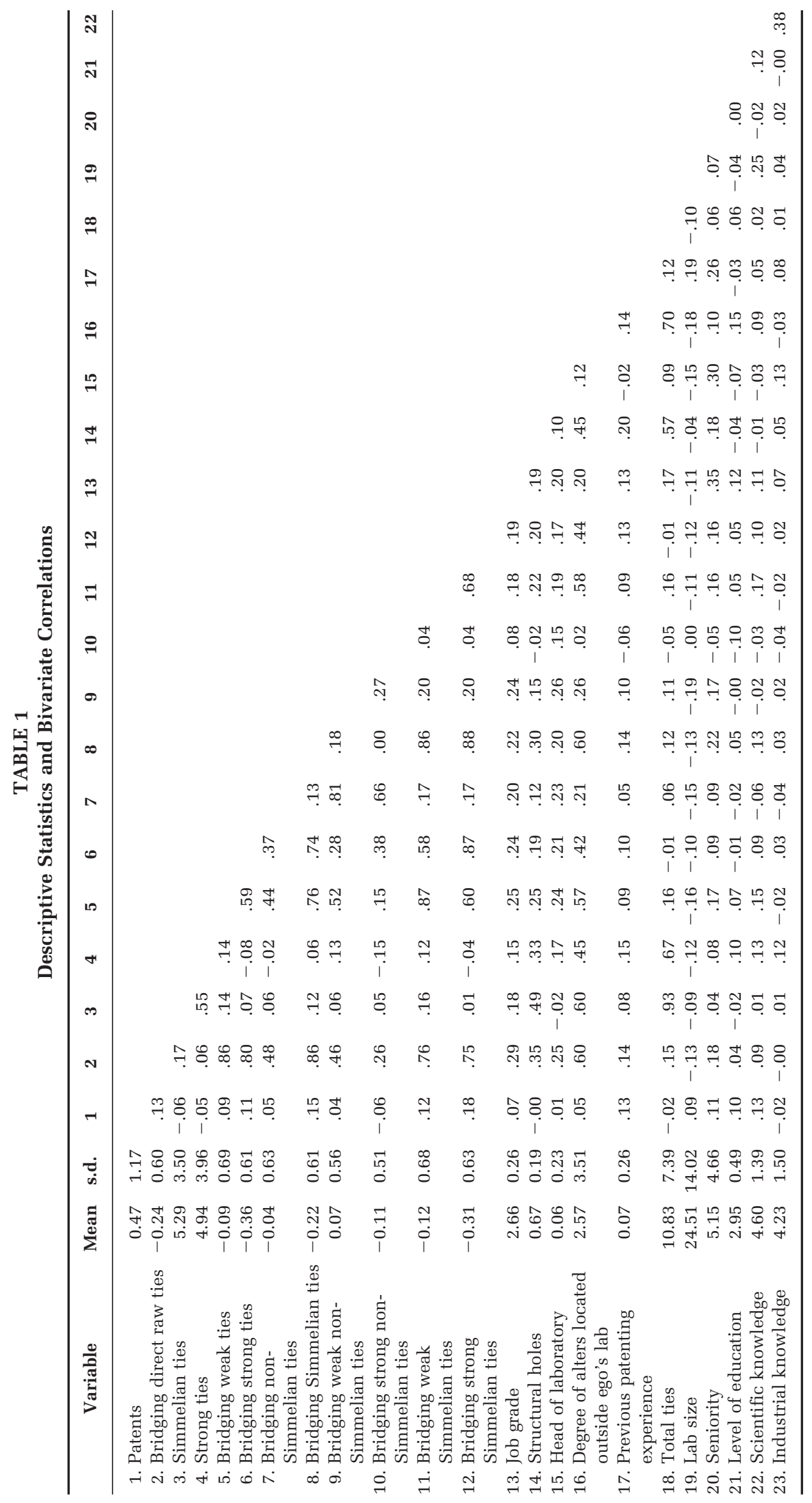




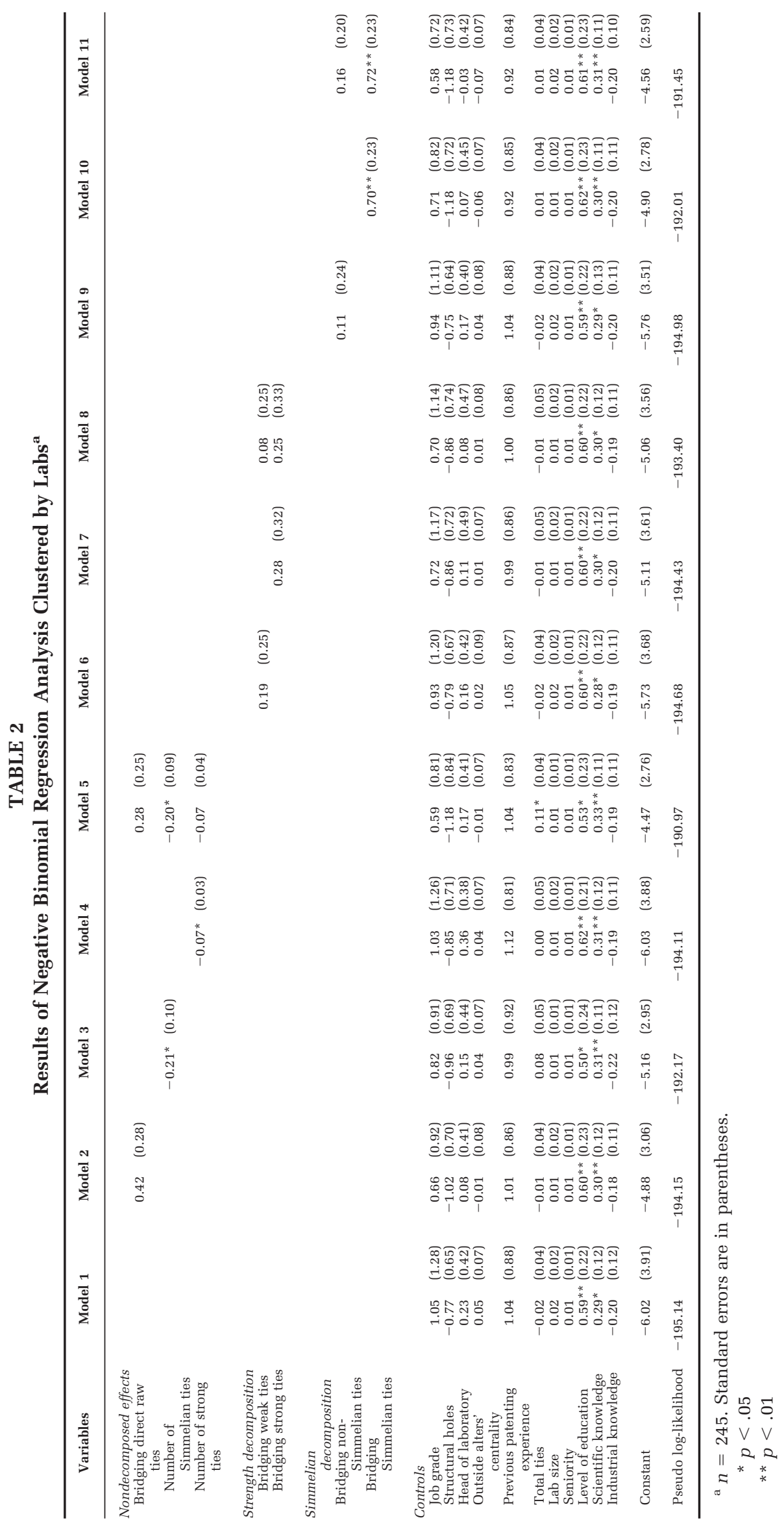


observe that bridging non-Simmelian ties are not significantly associated with individual innovativeness, but that the coefficient for bridging Simmelian ties is positively and significantly associated with the generation of innovations $(p=0.002)$. Results did not change when we put both variables into the same equation (model 11). Moreover, the estimates reported in models 9 and 10 reveal that the coefficient for bridging non-Simmelian ties (0.11) falls outside the boundaries of the $95 \%$ confidence interval of the coefficient for bridging Simmelian ties (0.26-1.14), providing direct support for Hypothesis 2. That is, bridging Simmelian ties is indeed significantly more strongly associated with patent generation than bridging non-Simmelian ties.

Although the results presented in Table 2 suggested that strength of bridging ties per se has no bearing on individual innovativeness, the relationship between Simmelian bridges and strong bridges warranted further examination.

Specifically, whereas the models in Table 2 measure weak/strong ties and Simmelian/non-Simmelian ties separately, it is nonetheless possible to combine these four types of ties to determine more precisely their relative contributions to individual innovativeness. In Table 3, we provide the results of a different set of analyses whereby we tried to ascertain the extent to which strength of ties matters when considered in the context of Simmelian versus non-Simmelian ties. In particular, by taking tie strength into account, we defined four mutually exclusive and exhaustive categories of network ties and evaluated the extent to which they bridged organizational boundaries by computing the E-I index for each. The four categories were (1) weak non-Simmelian ties, (2) strong non-Simmelian ties, (3) weak Simmelian ties, and (4) strong Simmelian ties.

In model 1, Table 3, we observe that there are no advantages associated with non-Simmelian weak bridges. In keeping with our previous findings, model 2 shows that strong non-Simmelian bridges are not significantly associated with the generation of innovation (the sign is actually negative). Models 4 and 5 reinforce our prior results by showing a significant association between strong Simmelian bridges and the generation of innovation. Interestingly, though, model 3 reveals that bridging weak Simmelian ties is only modestly (and nonsignificantly) associated with innovative output. Moreover, this weak association virtually disappears in the full model (model 5). That is, the contribution that Simmelian ties make to this innovative process only occurs when these ties are also strong.

The results presented in Table 3 are intriguing, as they further refine our understanding of the conditions under which bridging ties contribute to the

TABLE 3

Results of Negative Binomial Regression Models for Number of Patent Applications ${ }^{\text {a }}$

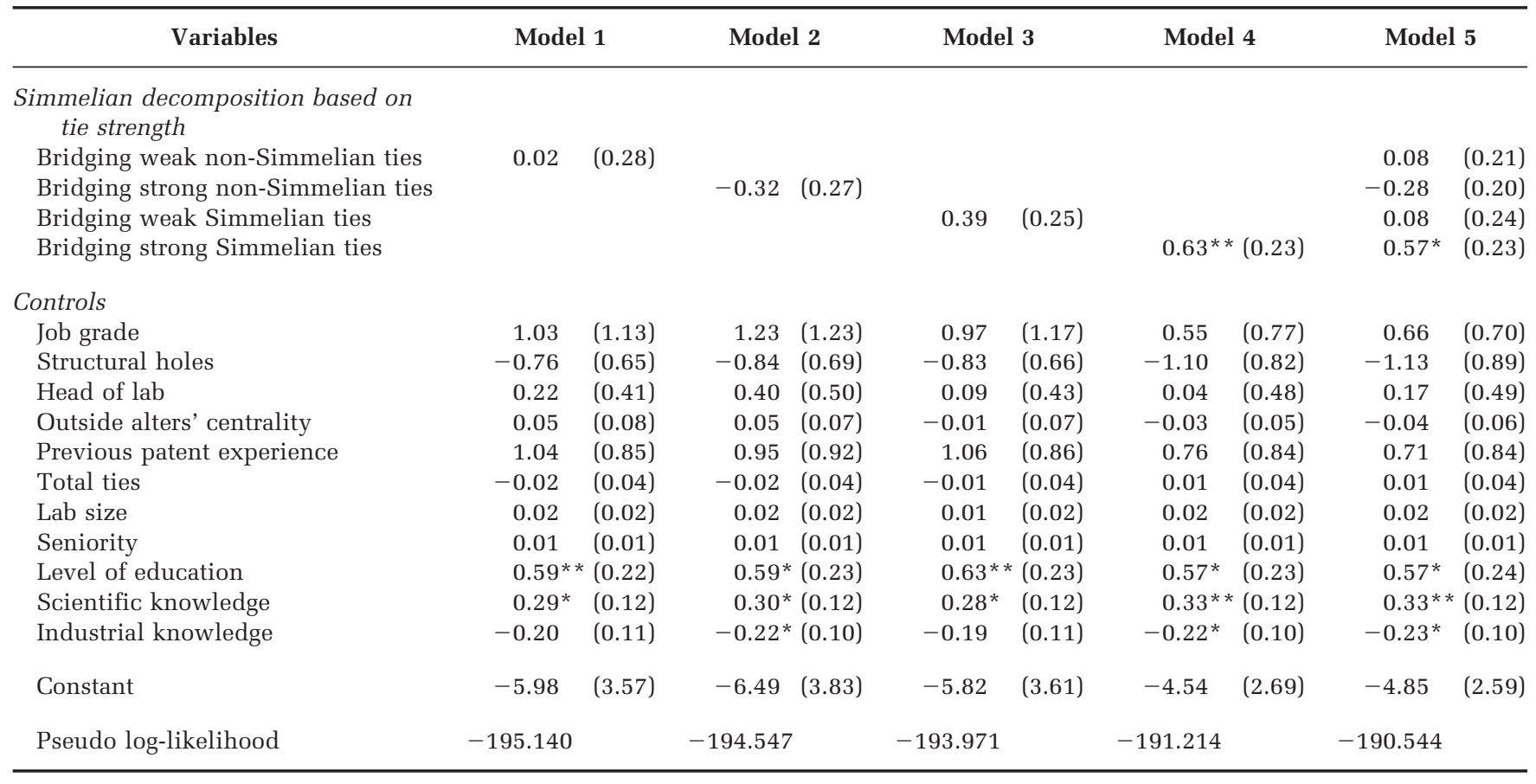

\footnotetext{
${ }^{\mathrm{a}} n=245$. Standard errors are in parentheses.

${ }^{*} p<.05$

${ }^{* *} p<.01$
} 
generation of individual innovativeness. Although Table 2 indicated that only the Simmelian nature of the ties mattered (and that strength of tie did not matter), Table 3 reveals that strength of ties does make a difference in a Simmelian context. As shown in the bar chart in Figure 1, a comparison of the magnitudes of effects for different types of bridging ties suggests that it is not only strong bridging ties that do not improve significantly over the baseline effect of bridging computed on direct raw ties (the coefficient is actually lower), but also that only Simmelian ties bridging boundaries (model 10, Table 2) and strong Simmelian ties bridging boundaries (model 4, Table 3) significantly increase the likelihood of patent generation. Implications of these results are discussed in detail in the next section.

\section{DISCUSSION}

Previous research on boundary spanning and innovation has focused on direct links between individual players and the positions that these players occupy in a macrostructural tapestry. In this study, we focus attention on the contribution of Simmelian bridges to this process. Since Simmelian ties are traditionally thought of as not providing bridging opportunities, the concept of a Simmelian bridge might at first seem counterintuitive. However, since in our case bridging refers to the act of spanning formal (i.e., intraorganizational) rather than informal (i.e., social) boundaries, a Simmelian tie, like any other kind of tie, can be a bridge when laid across formally bounded units. Our analysis further provides evidence for the fact that, unlike many other kinds of bridging ties, a Simmelian bridge has a positive and significant association with individuals' ability to generate innovations.

This finding represents a deviation from standard research on social structure and innovation. Abundant research in this area has suggested that bridging ties are important for the generation of innovations (Burt, 1992, 2004; Hargadon, 2002), but we instead suggest that, in the context of crossboundary relationships, the positive effects of bridging on innovation reflect the specific features of a subset of network ties: Simmelian ties.

We contend that these findings are relevant because they provide a finer-grained view of the relationship between bridging ties, strength of ties, and social structure. Specifically, our findings reveal that the distinction between weak and strong bridging ties is not very informative if the dyad forming a bridge is considered independently of the microcontext in which it is embedded. In our research setting, it was not the strength of a bridging tie per se that explained variation in individuals' innovative capabilities, but rather, whether or not a strong bridging tie was embedded in a dense cliquelike structure.

An interesting question arises from this confound. Simmelian ties are often stronger than nonSimmelian ties. If one were to only measure the strength of ties spanning formally bounded groups

FIGURE 1

Effects of Bridging Intraorganizational Boundaries on the Likelihood of Patent Generation, by Type of Tie

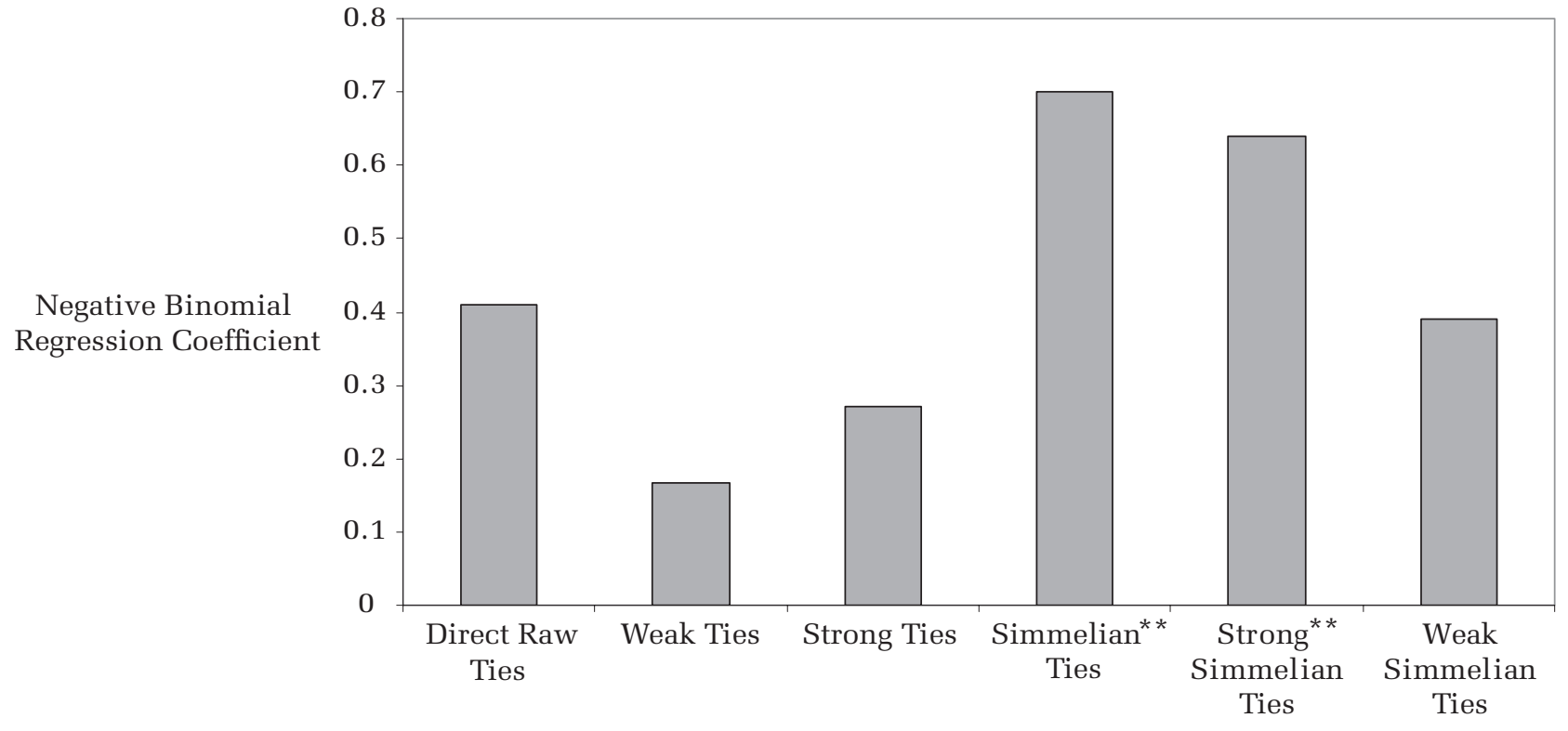

${ }^{* *} p<.01$ 
and not whether such ties were Simmelian, one might observe a relationship between tie strength and innovation that is really a function of the (unobserved) embedded nature of the tie. Is it possible that prior research underscoring the benefits of strong ties has really been based on this spurious relationship? Future, more thorough work on this question is certainly called for.

Our study also makes an important contribution to current research on social networks and performance. The traditional identification of bridging advantages with ties spanning holes in an informal (social) structure ignores the case in which Simmelian ties span holes defined by a formal (organizational) structure, thus leading to underestimation of the impact of social structure on performance in organizations. ${ }^{12}$ Results presented here suggest instead that Simmelian bridges can be an important complement to current research practice in social network research that has operationalized the advantages of bridging through more traditional measures such as constraint/structural holes (Burt, 1992) and betweenness centrality (Freeman, 1979).

Our study also contributes to research on knowledge management and innovation by showing that the ability to integrate and reconcile heterogeneous knowledge sets accessed through bridging ties should not be taken for granted. In this sense, our findings are consistent with much research on innovation and new product development (Bechky, 2003; Carlile, 2004; Dougherty, 1992) while also offering a more nuanced view of the advantages provided by bridging ties. In particular, we specified some structural conditions for the nature of ties spanning formal boundaries (i.e., their being embedded in cliques) that warrant further examination in future research.

Our call for more research in this area stems in part from recognized limitations of the current study. For example, an important element to consider is that the ability to reconcile different perspectives and gain advantage from knowledge diversity through collaboration and interactions could also vary with the degree of knowledge diversity. Our study did not, however, capture how similar or different knowledge was across different boundaries, and this constrained our ability to evaluate the threshold above which knowledge becomes too diverse to be fruitfully reconciled and synthesized into some form of innovative output.

Another limitation is the potential for endogeneity and reverse causality in our research design.

${ }^{12}$ We are indebted to an anonymous reviewer for suggesting this point.
The possibility of endogeneity arises because more innovative people have idiosyncratic features (experience, talent, abilities, expertise) that differentiate them from their colleagues and that could explain not just their ability to generate innovations but also their positions in an overall social structure. In the context of industrial R\&D labs, colleagues may seek out more skilled/knowledgeable individuals more frequently than others because of their knowledge and abilities.

Although this reverse-causality explanation of our results is a possibility, for several reasons the threat of endogeneity in our empirical models is likely to be minimal. First of all, the models presented here included several individual-level covariates as controls for important differences in individuals' experience, ability, and knowledge. As has previous research on social networks and knowledge management (Cross \& Cummings, 2004; Reagans \& McEvily, 2003; Reagans \& Zuckerman, 2001), in all models we controlled for organizational tenure (as a proxy for experience), level of education and organizational job grade (as proxies for knowledge and ability), type of knowledge sourced from outside (as a proxy for knowledge and expertise), and prior patenting experience (as a proxy for ability and expertise). Although not comprehensive, these variables do control for much of the "unobserved heterogeneity" in individuals' ability to generate innovations. The effects of bridging Simmelian ties on individual innovativeness persist and retain statistical significance exceeding the effects of the individual-level control variables.

In addition, the pattern of results obtained is hard to reconcile with a theory based on reverse causality. For instance, we found that only a subset of network ties defined across organizational boundaries was positively associated with patent applications. This finding is difficult to explain in terms of endogeneity. Actually, if reverse causality were operating in our context, we would expect the relationship between network ties and innovativeness to be the same independently of the features of ties considered. In particular, if more innovative individuals are more sought after by their colleagues, who seek to benefit from their knowledge and expertise to generate more patents, we would expect to observe a significant effect for network size (i.e., total size) on innovation.

Another important element to point out is that we collected our network data in a single R\&D organization at a given time in its development. Specifically, individuals in our sample had relatively low average tenure, suggesting that this is an organization in formation. It would be interesting to evaluate how our results generalize to different 
types of organizations, and in particular how they generalize to contexts characterized by longer operational experience.

In spite of these limitations, our study is important because it provides evidence for how Simmelian bridging ties characterize and define the informational advantages traditionally associated with bridging ties. By considering the relationships between formal and informal structure, we show that individuals can occupy positions that are advantageous in terms of knowledge and opportunities but that, at the same time, leverage the benefits associated with a supportive and cohesive network of relationships that promotes cooperation and coordination of joint activities (Burt, 2005). The benefits of this integrative approach to social capital can easily be extended to a variety of organizational phenomena. For instance, career advancement inside an organization might require vision more than opportunities and information (Burt, 1992, 1997) yet also require support from key actors based on a proven loyalty and trust developed through repeated interactions. Similarly, one's access to rewarding opportunities might be determined by the interplay between knowing that such opportunities exist and knowing how to leverage one's system of political support to get there (Krackhardt, 1990).

In this article, we build on the classical idea of bridging by considering the microstructure in which bridging ties are embedded. Bridging standard ties, or even strong ties, only marginally contributed to productivity in these data, but bridging Simmelian ties significantly and substantially improved individual innovative performance. We hope these findings will stimulate more research in the area of social networks and performance in which the differential effect and the role of Simmelian ties is explicitly considered as an important aspect of structural analysis.

\section{REFERENCES}

Ahuja, G. 2000. Collaboration networks, structural holes and innovation: A longitudinal study. Administrative Science Quarterly, 45: 425-455.

Allen, T. J., \& Cohen, S. I. 1969. Information flow in research and development laboratories. Administrative Science Quarterly, 14: 12-19.

Allen, T. J., Tushman, M. L., \& Lee, M. S. 1979. Technology transfer as as function of position in the spectrum from research through development to technical services. Academy of Management Journal, 22: $684-708$.

Ancona, D., \& Caldwell, D. F. 1992. Bridging the boundary: External activity and performance in organiza- tional teams. Administrative Science Quarterly, 37: $634-665$.

Argote, L. 1999. Organizational learning: Creating, retaining, and transferring knowledge. Boston: Kluwer Academic.

Bechky, B. A. 2003. Sharing meaning across occupational communities: The transformation of knowledge on a production floor. Organization Science, 14: 312-330.

Burt, R. S. 1992. Structural holes: The social structure of competition. Cambridge, MA: Harvard University Press.

Burt, R. S. 1997. The contingent value of social capital. Administrative Science Quarterly, 42: 339-365.

Burt, R. S. 2000. The network structure of social capital. In R. I. Sutton \& B. M. Staw (Eds.), Research in organizational behavior, vol. 22: 345-423. Greenwich, CT: JAI Press.

Burt, R. S. 2002. Bridge decay. Social Networks, 24: 333-363.

Burt, R. S. 2004. Structural holes and good ideas. American Journal of Sociology, 110: 349-399.

Burt, R. S. 2005. Brokerage and closure: An introduction to social capital. Oxford, U.K.: Oxford University Press.

Carley, K. M., \& Krackhardt, D. 1996. Cognitive inconsistencies and non-symmetric friendship. Social Networks, 18: 1-27.

Carlile, P. R. 2002. A pragmatic view of knowledge and boundaries: Boundary objects in new product development. Organization Science, 13: 442-455.

Carlile, P. R. 2004. Transferring, translating and transforming: An integrative and relational approach to sharing and assessing knowledge across boundaries. Organization Science, 15: 555-568.

Carlile, P. R., \& Rebentisch, E. S. 2003. Into the black box: The knowledge transformation cycle. Management Science, 49: 1180-1195.

Chesbrough, H. 2003. Open innovation. Cambridge, MA: Harvard University Press.

Cohen, W. M., \& Levinthal, D. A. 1990. Absorptive capacity: A new perspective on learning and innovation. Administrative Science Quarterly, 35: 128-152.

Coleman, J. S. 1988. Social capital in the creation of human capital. American Journal of Sociology, 94: 95-120.

Cross, R., \& Cummings, J. N. 2004. Tie and network correlates of individual performance in knowledgeintensive work. Academy of Management Journal, 47: 928-937.

Dekker, D. 2006. Measures of Simmelian tie strength, Simmelian brokerage, and Simmelianly brokered. Journal of Social Structure, 7(1): 1-22.

Dougherty, D. 1992. Interpretive barriers to successful product innovation in large firms. Organization Science, 3(2): 179-202. 
Freeman, L. A. 1979. Centrality in social networks: Conceptual clarification. Social Networks, 1: 215-239.

Granovetter, M. S. 1982. The strength of weak ties: A network theory revisited. In P. V. Marsden \& N. Lin (Eds.), Social structure and network analysis: 105130. Beverly Hills, CA: Sage.

Hansen, M. 1999. The search-transfer problem: The role of weak ties in sharing knowledge across organization subunits. Administrative Science Quarterly, 44: 82-111.

Hargadon, A. 2002. Brokering knowledge: Linking learning and innovation. In B. M. Staw \& R. M. Kramer (Eds.), Research in organizational behavior, vol. 24: 41-85. Greenwich, CT: JAI Press.

Krackhardt, D. 1987. Cognitive social structures. Social Networks, 9: 109-134.

Krackhardt, D. 1990. Assessing the political landscape: Structure, cognition, and power in organizations. Administrative Science Quarterly, 35: 342-369.

Krackhardt, D. 1992. The strength of strong ties: The importance of philos in organization. In N. Nohria \& R. G. Eccles (Eds.), Networks and organizations: 216-239. Boston: Harvard Business School Press.

Krackhardt, D. 1998. Simmelian tie: Super strong and sticky. In R. M. Kramer \& M. A. Neale (Eds.), Power and influence in organizations: $21-38$. Thousand Oaks, CA: Sage.

Krackhardt, D. 1999. The ties that torture: Simmelian tie analysis in organizations. In S. B. Andrews \& D. Knocke (Eds.), Research in the sociology of organizations, vol. 16: 183-210. Greenwich, CT: JAI Press.

Krackhardt, D., \& Stern, R. 1988. Informal networks and organizational crisis: An experimental simulation. Social Psychology Quarterly, 51: 123-140.

Laursen, K., \& Salter, A. 2006. Open for innovation: The role of openness in explaining innovation performance among U.K. manufacturing firms. Strategic Management Journal, 27: 131-150.

Lawrence, P., \& Lorsch, J. 1967. Differentiation and integration in complex organizations. Administrative Science Quarterly, 12: 1-30.

McEvily, B., \& Zaheer, A. 1999. Bridging ties: A source of firm heterogeneity in competitive capabilities. Strategic Management Journal, 20: 1133-1156.

Mors, M. L. 2010. Innovation in a global consulting firm: When the problem is too much diversity. Strategic Management Journal: In press.

Obstfeld, D. 2005. Social networks, the tertius iungens orientation, and involvement in innovation. Administrative Science Quarterly, 50: 100-130.

Perry-Smith, J. E. 2006. Social yet creative: The role of social relationships in facilitating individual creativity. Academy of Management Journal, 49: 85-101.
Reagans, R., \& McEvily, B. 2003. Network structure and knowledge transfer: The effects of cohesion and range. Administrative Science Quarterly, 48: 240-267.

Reagans, R., \& Zuckerman, E. 2001. Network, diversity and performance: The social capital of R\&D units. Organization Science, 12: 502-517.

Simmel, G. 1950. The sociology of George Simmel [K. H. Wolff, Ed.]. Glencoe, IL: Free Press.

Simon, H. A. 1985. What we know about the creative process. In R. L. Kuhn (Ed.), Frontiers in creative and innovative management: 3-20. Cambridge, MA: Ballinger.

Tsai, W. P. 2001. Knowledge transfer in intraorganizational networks: Effects of network position and absorptive capacity on business unit innovation and performance. Academy of Management Journal, 44: 996-1004.

Tushman, M. 1977. Special boundary roles in the innovation process. Administrative Science Quarterly, 22: $587-605$

Tushman, M., \& Scanlan, T. J. 1981. Characteristics and external orientations of boundary spanning individuals. Academy of Management Journal, 24: 83-98.

Utterback, J. M. 1971. The process of technological innovation within the firm. Academy of Management Journal, 14: 75-88.

Uzzi, B. 1997. Social structure and competition in interfirm networks: The paradox of embeddedness. Administrative Science Quarterly, 42: 35-67.

von Hippel, E. 1994. "Sticky information" and the locus of problem solving: Implication for innovation. Management Science, 40: 429-439.

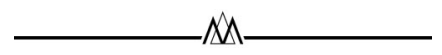

Marco Tortoriello (mtortoriello@iese.edu) is an assistant professor of strategic management at IESE Business School. He received his Ph.D. in organizational behavior and theory from the Tepper School of Business, Carnegie Mellon University. His research focuses on the mechanisms through which social structure affects the distribution and utilization of knowledge within and across organizations and how that relates to individual innovative capabilities.

David Krackhardt (krack@cmu.edu) is a professor of organizations at the Heinz School of Public Policy and Management and at the Tepper School of Business, Carnegie Mellon University. He received his Ph.D. from the University of California, Irvine. He studies the causes and consequences of social networks in organizations. He also develops methodologies designed to help organizational scholars pursue social network research.

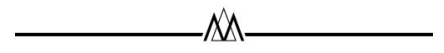

